\title{
Effects of Distortion on Mass Flow Plug Calibration
}

\author{
Jonathan Sasson $^{1}$ \\ Case Western Reserve University, Cleveland, OH, 44106 \\ David O. Davis ${ }^{2}$ \\ NASA Glenn Research Center, Cleveland, OH, 44135 \\ and \\ Paul J. Barnhart ${ }^{3}$ \\ Case Western Reserve University, Cleveland, OH, 44106
}

\begin{abstract}
A numerical, and experimental investigation to study the effects of flow distortion on a Mass Flow Plug (MFP) used to control and measure mass-flow during an inlet test has been conducted. The MFP was first calibrated using the WIND-US flow solver for uniform (undistorted) inflow conditions. These results are shown to compare favorably with an experimental calibration under similar conditions. The effects of distortion were investigated by imposing distorted flow conditions taken from an actual inlet test to the inflow plane of the numerical simulation. The computational fluid dynamic (CFD) based distortion study only showed the general trend in mass flow rate. The study used only total pressure as the upstream boundary condition, which was not enough to define the flow. A better simulation requires knowledge of the turbulence structure and a specific distortion pattern over a range of plug positions. It is recommended that future distortion studies utilize a rake with at least the same amount of pitot tubes as the AIP rake.
\end{abstract}

\section{Nomenclature}

$\begin{array}{ll}A R & =\text { Area ratio } \\ C_{D} & =\text { discharge coefficient } \\ K_{A 2} & =\text { radial and circumferential distortion descriptor } \\ K_{r} & =\text { radial distortion descriptor } \\ K_{\theta} & =\text { circumferential distortion descriptor } \\ \dot{m} & =\text { mass flow rate } \\ M & =\text { Mach number } \\ P & =\text { pressure } \\ q & =\text { dynamic pressure } \\ r & =\text { radius } \\ R & =\text { specific gas constant } \\ T & =\text { temperature } \\ w & =\text { corrected flow } \\ \gamma & =\text { specific heat ratio } \\ \rho & =\text { density }\end{array}$

\section{Subscripts}

calc $=$ calculated value

eff $\quad=$ effective

$T=$ total (stagnation) condition

\footnotetext{
${ }^{1}$ Student, Mechanical and Aerospace Engineering Dept., AIAA Student Member.

${ }^{2}$ Aerospace Engineer, Inlet and Nozzle Branch, Senior AIAA Member.

${ }^{3}$ Associate Professor, Mechanical and Aerospace Engineering Dept., Professional AIAA Member.
}

American Institute of Aeronautics and Astronautics 


\section{Introduction}

Supersonic aircraft inlets are routinely tested in NASA Glenn Research Center (GRC) larger wind tunnels such as the 8x6ft and 10x10ft Supersonic Wind Tunnels (SWT). Two key objectives of such tests are to prove that the inlet mass capture matches the engine mass flow demand, and stable inlet operation is possible over a range of mass flows. Therefore accurate inlet mass flow measurement is of primary importance ${ }^{1}$. Due to its simple mechanical design, the mass flow through an inlet is often controlled and measured by a conical Mass Flow Plug (MFP).

To achieve the highest mass flow measurement accuracy, the mass flow plug must be calibrated prior to testing. Most often, calibration of the mass flow plug is performed with well-defined, uniform flow conditions. During inlet testing shockwave/boundary-layer interactions and flow separation in the subsonic diffuser can significantly distort the flow approaching the MFP. To mitigate the effects of distortion on the mass flow plug calibration, the recommended practice is to provide at least 10 diameters of development length ahead of the mass flow plug (MFP) is recommended. On larger scale inlets models or in applications where there are multiple engines, a pipe length of 10 diameters is not always practical so the effects of flow distortion must be accounted for during the calibration.

The consequences of distortion on intake testing are apparent in a recent test performed by Boeing ${ }^{2}$ where they characterized the flow through an inlet integrated onto a low-boom supersonic cruise aircraft concept in NASA Glenn Research Center's (GRC) 8x6ft SWT. Figure 1 shows a photograph of the Boeing Quiet Experimental Validation Concept (QEVC) model installed in the 8x6ft SWT with the MFP prominently featured on the starboard side. The MFP was close-coupled to the inlet as shown. In Fig. 2 the rakes at the Aerodynamic Interface Plane (AIP) station characterize the flow that would enter the engine and the rakes at the MFP station are used for calibration of the MFP. Prior to the 8x6ft SWT test, Boeing experimentally calibrated the MFP under undistorted flow conditions. During the $8 \times 6 \mathrm{ft}$ SWT inlet test, the flow conditions, with various levels of flow distortion, were recorded at the AIP and MFP rake stations. The levels of total pressure distortion were high enough to question whether the MFP calibration could be used reliably to determine the flow rate through the inlet. Following testing, a numerical investigation was undertaken to understand and quantify how flow distortion affects mass flow measurement in the present configuration. The results of the post-test numerical investigation are reported herein.

\section{Analysis Methodology}

In order to quantify the effects of flow distortion on the MFP flow rate, a numerical investigation of the flow through the MFP has been performed for both undistorted and distorted approach flow conditions. This investigation consists of the following steps. First, a numerical calibration of the MFP with undistorted approach flow is performed and compared to the experimental calibration. Favorable agreement with CFD simulations will demonstrate that the numerical simulations are correctly capturing the flow physics. The second step is to apply a range of distorted flow fields as inflow boundary conditions at the AIP station and compare the resulting flow rate to that flow rate derived from the undistorted calibration. The final step is to use the resulting undistorted and distorted flow data sets to develop a correction correlation.

All of the numerical simulations were performed using WIND-US, which is a general purpose 3-D Reynoldsaveraged Navier-Stokes (RANS) flow solver ${ }^{3}$. WIND-US is a mature, multi-zone, structured compressible flow solver offering a variety of turbulence models. All the calculations were performed in steady-state using the Menter Shear Stress Transport (SST) turbulence model $^{3}$. Previous studies have shown this particular model performs well for jet flows ${ }^{4,5,6}$. The details and results of this procedure are expanded upon in the following sections.

\section{A. Numerical Calibration}

An axisymmetric structured grid, consisting of approximately two million grid points and divided into 18 zones, is used to model the calibration rig shown in Fig. 3. Grids were created for 10 different plug positions corresponding to the experimental calibration positions. An example grid is shown in Fig. 4.

The inflow plane is located upstream of the 22:1 bellmouth and coincides with the rakes at the inflow station (see Fig. 2 and 3). The total pressure and total temperature at the inflow plane was uniform and matched the average measured values of the experimental calibration. For the numerical simulations, the rakes at the AIP and MFP stations were not modeled and all zones assume turbulent flow.

Due to the simple nature of the geometry and grid, there was no need to run each case with grid sequencing. Every plug position was computed with a fine sequence using every point. The simulations used a constant CourantFriedichs-Lewy (CFL) number of 1 . Solution convergence was achieved when the mass flow rate in each zone of the divergence and cold pipe did not vary by more than $0.0001 \mathrm{lb} / \mathrm{s}$. The mass flow was computed at each grid point of these zones.

American Institute of Aeronautics and Astronautics 


\section{B. Flow with Distortion}

Due to the asymmetrical nature of distortion, it is not trivial to create an analysis routine using a simple 1-D control volume method. It is necessary to account for shearing flows with variations azimuthally. Swirl is another phenomenon that arises. To capture the effects of distortion, computational fluid dynamics (CFD) simulations were used to solFve for the internal flow in the calibration rig. For the distorted flow investigation, 35 cases taken from the inlet test were selected for comparison. The 35 cases are summarized in Table 1.

Table 1. Distortion cases.

\begin{tabular}{|c|c|c|c|c|c|c|}
\hline \multirow{2}{*}{ Case } & \multirow{2}{*}{ Position } & \multirow{2}{*}{ Area ratio } & \multirow{2}{*}{$M_{A I P}$} & \multirow{2}{*}{$D I S T_{A I P}$} & \multicolumn{2}{|c|}{$D I S T_{M F P}$} \\
\hline & & & & & Experimental & CFD \\
\hline 1 & 1 & 0.457 & 0.553 & 0.246 & 0.167 & 0.172 \\
\hline 2 & 1 & 0.456 & 0.564 & 0.251 & 0.181 & 0.173 \\
\hline 3 & 1 & 0.456 & 0.564 & 0.254 & 0.182 & 0.174 \\
\hline 4 & 1 & 0.456 & 0.594 & 0.335 & 0.201 & 0.244 \\
\hline 5 & 1 & 0.456 & 0.567 & 0.268 & 0.157 & 0.198 \\
\hline 6 & 1 & 0.456 & 0.572 & 0.279 & 0.198 & 0.198 \\
\hline 7 & 2 & 0.440 & 0.516 & 0.193 & 0.135 & 0.131 \\
\hline 8 & 2 & 0.440 & 0.592 & 0.397 & 0.243 & 0.294 \\
\hline 9 & 2 & 0.440 & 0.529 & 0.225 & 0.169 & 0.170 \\
\hline 10 & 2 & 0.440 & 0.526 & 0.217 & 0.129 & 0.166 \\
\hline 11 & 2 & 0.440 & 0.517 & 0.188 & 0.124 & 0.128 \\
\hline 12 & 2 & 0.440 & 0.510 & 0.188 & 0.130 & 0.139 \\
\hline 13 & 3 & 0.432 & 0.495 & 0.152 & 0.111 & 0.107 \\
\hline 14 & 3 & 0.432 & 0.493 & 0.166 & 0.108 & 0.126 \\
\hline 15 & 3 & 0.432 & 0.525 & 0.258 & 0.181 & 0.212 \\
\hline 16 & 4 & 0.423 & 0.492 & 0.178 & 0.123 & 0.179 \\
\hline 17 & 4 & 0.423 & 0.532 & 0.327 & 0.205 & 0.323 \\
\hline 18 & 4 & 0.423 & 0.478 & 0.151 & 0.098 & 0.140 \\
\hline 19 & 4 & 0.423 & 0.485 & 0.106 & 0.094 & 0.111 \\
\hline 20 & 4 & 0.423 & 0.490 & 0.183 & 0.153 & 0.186 \\
\hline 21 & 5 & 0.415 & 0.468 & 0.095 & 0.094 & 0.099 \\
\hline 22 & 5 & 0.415 & 0.464 & 0.144 & 0.092 & 0.131 \\
\hline 23 & 5 & 0.415 & 0.484 & 0.193 & 0.139 & 0.196 \\
\hline 24 & 6 & 0.406 & 0.484 & 0.247 & 0.148 & 0.239 \\
\hline 25 & 6 & 0.406 & 0.451 & 0.145 & 0.101 & 0.144 \\
\hline 26 & 7 & 0.397 & 0.442 & 0.160 & 0.105 & 0.144 \\
\hline 27 & 7 & 0.397 & 0.467 & 0.221 & 0.113 & 0.201 \\
\hline 28 & 7 & 0.396 & 0.445 & 0.157 & 0.095 & 0.154 \\
\hline 29 & 8 & 0.387 & 0.426 & 0.130 & 0.093 & 0.132 \\
\hline 30 & 8 & 0.387 & 0.427 & 0.069 & 0.074 & 0.076 \\
\hline 31 & 8 & 0.387 & 0.428 & 0.075 & 0.068 & 0.080 \\
\hline 32 & 9 & 0.359 & 0.417 & 0.176 & 0.101 & 0.160 \\
\hline 33 & 10 & 0.349 & 0.376 & 0.052 & 0.055 & 0.057 \\
\hline 34 & 11 & 0.330 & 0.350 & 0.046 & 0.047 & 0.050 \\
\hline 35 & 11 & 0.330 & 0.350 & 0.054 & 0.043 & 0.054 \\
\hline
\end{tabular}

It is important to note that the CFD is not capturing all the details of the flow. Only the total pressure is measured and used as a boundary condition. None of the turbulence parameters are known, which are important to truly define the flow. For this reason, only profiles which exhibit no flow separation during testing are used in this analysis. The goal of the CFD analysis is to predict a discharged coefficient for the calibration rigs with and without distortion. The results are also used to determine a distortion parameter that characterizes the effects of distortion on the inlet test by Boeing and GRC. Boeing measured a significant level of total pressure distortion. 
The total pressure distortion was measured at the AIP. The measured distortion profiles are applied in the CFD as boundary conditions at the AIP. However, the test only includes pressure measurements at 40 discrete locations, which is not enough to apply a fine mesh consisting of 4,800 grid points. To convert to the finer mesh, the data is first spliced by a bicubic interpolation scheme to produce boundary conditions for the entire AIP (these are the inflow boundary conditions).

Since the boundary condition is applied at the AIP, there is no need to include any geometry upstream of it. Therefore the bellmouth is discarded in the distortion analysis. The grid is created by making a 2-D grid with the desired plug position, and then revolving it around the x-axis. A 3-D grid is necessary since the applied total pressure distortion profile is not symmetrical. The same surface boundary conditions as in the calibration case are applied at the surface of the mesh.

To reduce computational and convergence time with this mesh, the solution method employed parallel processing along with three levels of grid sequencing. First, a coarse grid sequence included only every fourth point in each direction. Second, a medium grid sequence utilized every other point in each direction. Third, a fine sequence used every grid point in the mesh.

The freestream static pressure this time is calculated from the measured total pressure. Once again, a total pressure is calculated with the wall static pressure to obtain the Mach number. The case matrix is found in the results section. Convergence is determined in the same manner as in the calibration case. The supercomputer cluster at NASA Ames was used for all CFD runs.

\section{Experimental Setup}

The MFP used in the 8x6ft SWT inlet test was calibrated at the $15 \times 15 \mathrm{~cm}$ SWT at NASA GRC for the purposes of this study. For the calibration, the inlet shown in Fig. 2 was replaced with a large $(22: 1)$ bellmouth contraction that was then attached to a settling chamber and an ASME nozzle drawing air from the atmosphere. The flow exiting the MFP exhausts into a test section maintained at around 1.75 psia (altitude exhaust). The resultant pressure ratio is 8.22 ensuring a choked MFP. The test geometry is shown in Fig. 5. Further details on the experimental calibration are presented in Ref. 7.

A single run consists of simply translating the MFP over an axial translation range specified later in this section. Before testing any distortion devices, a baseline calibration without any distortion generators is established.

\section{A. Rake Stations}

The AIP rake sits at the entrance of the 1.5 inch diameter diffuser. The rake follows the guidelines established in ARP 1420 to measure total pressure at the AIP $^{8}$. It represents an engine face plane which is defined by the leading edge of the most upstream engine strut, vane, or blade row. The station contains eight equally-spaced rakes with five pitot tubes per rake for a total of 40 total pressures. The pitot tubes are all area-weighted, i.e. the area covered by each ring is the same. Figure 6 represents the layout of the rake. The figure shows an upstream view of the rake; it represents the pressure distribution a compressor "sees". The nomenclature used in Fig. 6 that refers to the individual pitot tubes $(i, j)$ is per ARP2469. The ring number is defined by $i$, and the rake number by $j$.

The MFP rakes consist of four equally spaced rakes clocked so as to avoid the wakes of the upstream AIP rakes. Each of the MFP rakes has three total pressure probes and one thermocouple probe. There are no wall static taps at the MFP station. The tubes on both sets of rakes are positioned radially so as to have equal area weighting. The MFP rakes are shown in Fig. 7.

In addition, there are eight wall static pressure tap located azimuthally midway between the AIP rakes. The rakes and static pressure taps are connected to the ESP modules. Every other rake has one dynamic total pressure transducer for a total of four. These transducers (kulites) are not used during the experiment. They were used during the original Boeing calibration, and the $8 \times 6 \mathrm{ft}$ inlet test. They were left in place for consistency with the previous tests, and to help generate distortion.

\section{B. Distortion Generation}

Distortion is created by a ring, rapidly prototyped out of ABS plastic that fits in the throat of the bellmouth contraction 3 inches above the AIP. The screens and their maximum distortion level are shown in Table 2. Each ring has a mesh that partially covers different sections of the AIP. The mesh wire has a thickness and spacing of 0.125 inches. Each device is tested at three different orientations: 0, 22.5 and 337.5 degrees. The orientation is such that 0 degrees lines with AIP rake \#1. The goal is to create high pressure areas the MFP rakes will be able to capture. Several devices are tested to obtain levels of distortion at the MFP similar to those of the CFD study. The plug position is swept starting from the same position as in the calibration run, however it is stopped when the AIP Mach 
number is about 0.6. There are two reasons for this lower Mach number; to match the Mach numbers seen in the CFD study and to avoid breaking the mesh and damaging the pressure rakes.

Table 2. Distortion screens

\begin{tabular}{|c|c|c|c|c|c|}
\hline Screen \# & $\begin{array}{c}\text { Max. MFP } \\
\text { Distortion }\end{array}$ & Screen & Screen \# & $\begin{array}{c}\text { Max. MFP } \\
\text { Distortion } \\
\end{array}$ & Screen \\
\hline 2 & $6.21 \%$ & & 8.2 & $19.64 \%$ & \\
\hline 3 & $6.34 \%$ & & 9 & $18.08 \%$ & \\
\hline 7 & $17.72 \%$ & & 9.1 & $28.37 \%$ & \\
\hline 7.1 & $16.21 \%$ & & 12 & $5.15 \%$ & \\
\hline 7.2 & $19.62 \%$ & & 14 & $39.61 \%$ & \\
\hline 8 & $10.67 \%$ & & 15 & $37.09 \%$ & \\
\hline 8.1 & $21.76 \%$ & & & & \\
\hline
\end{tabular}


The rings with just a mesh create low levels of MFP distortion. To create the higher levels observed in the Boeing inlet test, parts of the mesh are blocked with duct tape. The idea is to create a low pressure area and a jet on the opposite side of the ring. The mesh is very thin, and at high speeds it may break and damage the pressure rakes. Duct tape makes the mesh more flexible. Two distortion rings are created that match the high and low pressure regions of AIP distortion observed during the inlet test.

\section{Discharge Coefficient}

The discharge coefficient for the plug is calculated from the flow measured by the ASME nozzle, and the calculated ideal flow rate. The details of the ASME nozzle and its calibration are found in Ref. 7. The discharge coefficient for the mass-flow plug is defined as:

$$
C_{D}=\frac{\dot{m}_{\text {actual }}}{\dot{m}_{\text {ideal }}}
$$

where $\dot{m}_{\text {actual }}$ is the actual mass flow through the cold pipe and is the ideal inviscid choked flow through the mass flow plug. The ideal mass-flow is calculated from the following equation

$$
\dot{m}_{\text {ideal }}=\frac{A^{*} P_{T}}{\sqrt{T_{T}}} \sqrt{\frac{\gamma}{R}}\left[\frac{\gamma+1}{2}\right]^{-\frac{\gamma+1}{2(\gamma-1)}}
$$

\section{Results}

For the numerical calibration, simulations were performed for MFP pressure ratios between 1.4 and 5.0, and at four plug positions (area ratios) spanning the range of the distortion data. These numerical calibration distributions are compared to the experimental distributions in Ref. 7. With the exception of the smallest area ratio, the distributions trend the same where the experimental discharge coefficient is slightly below the numerical value. This is likely due to the presence of the rakes in the experimental configuration contributing to slightly higher losses. For MFP pressure ratios greater than 2.0, the agreement is generally within $0.9 \%$. Further details are provided in Ref. 7.

The area ratio is defined as the throat area over the cold pipe's maximum cross-sectional area.

$$
A R=\frac{A^{*}}{A_{\max }}
$$

The minimum geometric area (or throat area) of the MFP is determined by assuming the sonic line to be perpendicular to surface, therefore the minimum geometric area is approximated by a curve, $f(x)$, that is both normal to the cone and the cold pipe's exit as shown in Fig. 8 and revolved around the x-axis.

\section{A. Non-Distorted Pressure Decay}

Although no distortion devices were used during the baseline calibration, some small amount of total pressure distortion was measured by the AIP and MFP probes. The distortion levels are defined by the difference of the maximum and minimum pressure divided by the average pressure at the corresponding face. This simple descriptor is typically used during inlet testing.

$$
D I S T=\frac{P_{T, \max }-P_{T, \min }}{\bar{P}_{T}}
$$

The AIP distortion is mostly radial and noticeable every other rake, where the kulites are located. The kulite blockage creates a small low pressure region around the AIP probes. The rest of the flow is unaffected by them. This is shown in Fig. 9a for the non-distorted case with the maximum pressure variation. Total pressure distortion grows downstream and is increased at the MFP due to viscous effects. These effects are evident in Fig. 9b where the total pressure has small radial variations at the MFP station. The small amount of distortion due to the kulites settles downstream and it is not very noticeable at the MFP. Both the AIP and MFP pressure readings are interpolated radially and azimuthally to produce smooth contours.

The results presented in Fig. 9c show the MFP distortion levels increasing linearly as AIP distortion increases. This corresponds to an increase in area ratio as the plug is opened. The CFD results do not detect any significant pressure variations at the AIP. Although the levels at the MFP are higher than the AIP, they are still not comparable 
to those measured experimentally for a given area ratio. The maximum error in the CFD results is $90 \%$. The CFD results are not reliable in measuring total pressure variations at a given face.

\section{B. Distorted Pressure Decay}

The variation between distortion at the AIP and MFP is presented in Fig. 10. The CFD distortion is measured by using only the 12 points that correspond to the probes' locations at the MFP station. Experimental distortion tends to decay more rapidly than the CFD would suggest. The CFD solution has a shallower, slope and it is not able to accurately predict how well the flow settles downstream. The AIP rakes, which are not modeled in the CFD study, act as crude screens effectively lowering the distortion levels. Increased turbulent mixing in the experiment also lowers the distortion levels. The CFD has no other information on the flow other than the total pressure at the AIP; it does not reflect the turbulence structure, streamwise gradients in the flow nor capture secondary flow component that might be present during inlet testing. The maximum deviation from the experimental values in the CFD results is $33 \%$.

Figure 10 also shows the actual MFP distortion levels measured during the inlet test. The CFD model is still not able to accurately predict how well the flow settles compared against the inlet results. The maximum deviation from the inlet test results is lower compared to the new experimental values (16:67\%), it is still not a good approximation. These results also include low distortion levels at the AIP not experienced during the inlet test. These levels are similar to those experienced during the test run under non-distorted conditions. In this region the viscous effects dominate and the distortion grows down the MFP.

\section{Distorted Discharge Coefficient}

To study the effects of total pressure distortion on the MFP calibration a total of 13 different devices were tested to obstruct the flow at the AIP. The experimental results are compared against CFD results. The CFD study consists of 35 different total pressure patterns at the AIP observed during the previous inlet test. The 35 patterns vary over 11 different plug positions. The experiment covers the range of plug positions used for the CFD results. As mentioned previously, the measured total pressure distribution is used as the upstream boundary condition. Each case takes an average of 50 hours to converge using grid sequencing and parallel processing.

The CFD results are presented in Fig. 11 as total pressure contours at the AIP and MFP face. Fig. 11a is the pressure profile at the AIP used as a boundary condition. The 40 total pressures and 8 static pressures are used to create 4,800 points for a fine grid. The average of the inner probe ring is used as the center pressure to create the inner region not measured during testing. Fig. $11 \mathrm{~b}$ is the measured profile at the MFP station during the inlet test. Fig. 11c is the CFD result at the MFP station using all 4,800 points, while Fig. 11d represents a profile created by extrapolating the pressures at the MFP probe locations and interpolating the results.

From Fig. 11c it is evident that the cold pipe is not long enough for the flow to settle. The distortion levels at Fig. 11b and Fig. 11d are 24.86\% and 27.87\% respectively. By comparing Fig. 11c to Fig. $11 \mathrm{~d}$ it is clear that the MFP rake profile is too coarse and misses a large section of the high pressure region. The MFP rake cannot capture enough points in the high pressure region to have a similar distortion levels compared to the full CFD solution. The distortion in Fig. 11c is $34.95 \%$.

The result of the MFP rake being too coarse is also observed during the experiment where the same distortion device was tested at three distinct circumferential locations. Although the distortion at the AIP only varied by 5\%, distortion at the MFP varied by as much as $15 \%$ in some cases by changing the orientation of the device at the same plug position. Various devices were tested, each with a different amount of blockage. Higher distortion levels were observed by leaving an open area and blocking another section, creating a high and low pressure region.

Figure 12 shows the results of using distortion device \#15.1 to recreate a similar distortion pattern observed in Fig. 11. The low pressure region measured in the experiment is much larger and not comparable to the inlet results. Thus screen 15.1 is not a good representation of the inlet distortion pattern. Distortion at the AIP varies between $55.58 \%$ and $60.57 \%$ depending on the orientation. The MFP distortion varies between $22.87 \%$ and $37.12 \%$. Both the CFD and inlet test results are in this range of distortion.

The distortion results for all screens are shown in Fig. 13. The y-axis is the difference between distorted and undistorted discharge coefficient divided by the undistorted discharge coefficient, $C_{D, u}$.

$$
\Delta C_{D}=C_{D, d}-C_{D, u}
$$

American Institute of Aeronautics and Astronautics 
The discharge coefficient is determined by using the upstream pressure to calculate the ideal mass flow rate. The results are compared against the CFD results. For the same range of distortion, the CFD under predicts the mass flow losses.

Although the experimental and CFD trend-lines have a different y-intercept, they follow the same trend of decreasing discharge coefficient as distortion increases. Distortion is a source of pressure loss and reduces the mass flow rate. There is a significant amount of scatter in the results shown in Fig. 13. The distorted behavior depends on the screen used to produce it. The scatter is reduced by looking at each screen individually. It is necessary to take into account the radial and circumferential effects of distortion to classify distortion.

Figures 14 through 18 represent the results for five individual screens and compared to their corresponding CFD solution when applicable. Not all screens match a certain CFD profile. Each figure represents a different mesh at three distinct orientations $\left(0^{\circ}, 22.5^{\circ}\right.$ and $\left.337.5^{\circ}\right)$. The results show that the distorted discharge coefficient is dependent not only on plug position, but also on the individual screens. Each screen has a different distortion pattern which may be defined by the $K_{A 2}$ and DIST descriptors. The results can be used to correct MFP results measured under distortion conditions but calibrated with undistorted flow, such as during Boeing's inlet test.

The $K_{A 2}$ descriptor takes into account both radial and circumferential total pressure distortion. It is defined as follows

$$
K_{A 2}=K_{\theta}+K_{r}
$$

where $K_{\theta}$ is the circumferential distortion and $K_{r}$ the radial distortion.

$$
\begin{gathered}
K_{\theta}=\frac{\sum_{i}^{N}\left[\frac{1}{r_{i}}\left\{\left(\sum_{j}^{M} P_{T} \cos \theta\right)^{2}+\left(\sum_{j}^{M} P_{T} \sin \theta\right)^{2}\right\}^{1 / 2}\right]}{\bar{q} \sum_{i}^{N} \frac{1}{r_{i}}} \\
K_{\theta}=\frac{\sum_{i}^{N}\left[\left(\frac{\bar{P}_{T}}{r_{i}^{2.8}}\right)\left(\frac{\Delta P R}{P}\right)_{i}\right]}{\bar{q} \sum_{i}^{N} \frac{1}{r_{i}^{2.8}}}
\end{gathered}
$$

where $\bar{q}$ is the average dynamic pressure expressed as

$$
\bar{q}=\frac{\gamma}{2} \bar{P} \bar{M}^{2}
$$

And the radial intensity element is defined by the difference between the face average total pressure at the AIP $\left(\bar{P}_{T}\right)$ and the ring average pressure, normalized by the AIP average total pressure.

$$
\left(\frac{\Delta P R}{P}\right)_{i}=\frac{\bar{P}_{T}-\bar{P}_{T, i}}{\bar{P}_{T}}
$$

NASA typically presents distortion results by correcting the flow by the arithmetic average of the total pressure at the MFP station. The pitot tubes are positioned in such a way that the average is area-weighted. The result of this correction is shown in Fig. 19. The y-axis shows the difference in weighted flow between the distorted, $w_{d}$, and undistorted cases, $w_{u}$.

$$
\Delta w=w_{d}-w_{u}
$$

The difference is normalized by the undistorted weighted flow. Both the experimental and CFD results show a significant amount of scatter around the trend-line. The maximum experimental error in the weighted flow is $0.85 \%$, therefore the trend-line is not very useful. The maximum deviation of the experimental results to the trend-line is $38.35 \%$. Using the trend-line to correct inlet tests is not reliable because of this scatter. Correcting the mass flow rate by the MFP total pressure shows an increase in flow rate, which contradicts the experimental results shown in Fig. 11.

American Institute of Aeronautics and Astronautics 
The MFP is extremely sensitive to distortion levels. Overall, the MFP presented in this chapter is of a poor design. The straight length segment of the cold pipe is not long enough to allow the flow to settle. Typical MFP configurations use a straight length segment of at least 12 plug diameters to avoid distortion. The straight length segment in this MFP is 3 diameters.

\section{Conclusion}

Total pressure distortion was created at the AIP to quantify its effects on the mass flow rate. Distortion was produced by rapidly prototyped meshes three inches upstream the AIP. The discharge coefficient for distorted conditions was as much as $30 \%$ lower compared to the baseline calibration. It is shown that deviation in discharge coefficient depends on both the $K_{A 2}$ and DIST distortion descriptors.

The MFP is sensitive to distortion and its effects on the mass flow rate cannot be accurately determined by correcting the flow by the MFP total pressure. The MFP is a flawed design since the straight length segment is too short and does not let the flow to settle. It is only 3 plug diameters in length, while most MFPs are at least 6 . A larger straight length segment is recommended in further testing of this MFP. The MFP station rakes are also too coarse and not able to capture all the total pressure variations across the face. In further distortion studies a rake with at least the same amount of pitot tubes as the AIP rake is recommended. The CFD distortion study only showed the general trend in mass flow rate but did not provide any useful insight to classify the distortion. The study uses only total pressure as the upstream boundary condition, which is not enough to define the flow. A better simulation requires knowledge of the turbulence structure, and a specific distortion pattern over a range of plug positions.

\section{Figures}

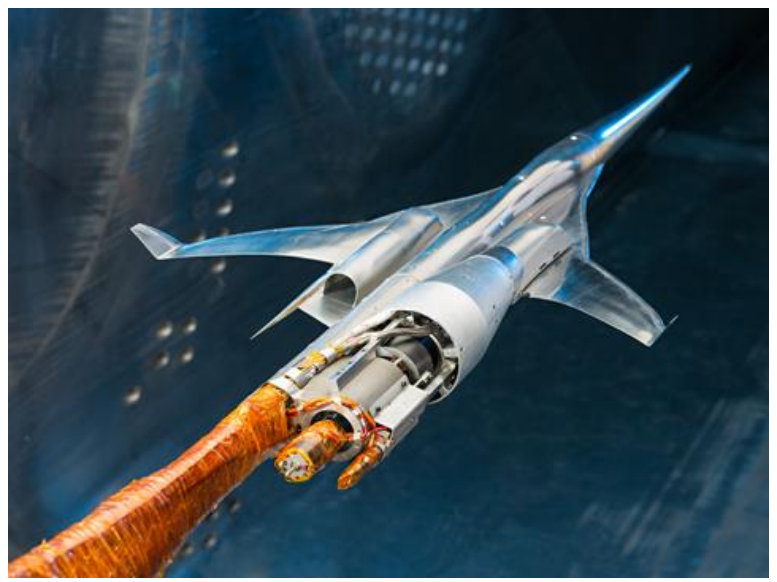

Figure 1. Low boom inlet test at NASA GRC.

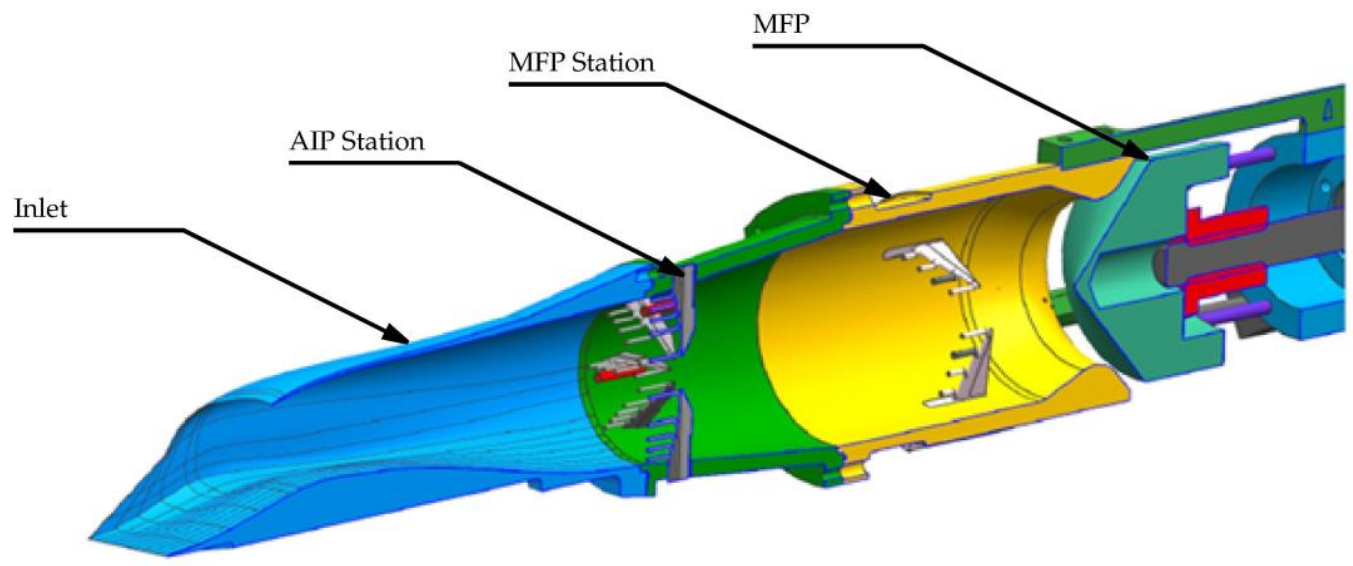

Figure 2. Low boom inlet/MFP configuration.

American Institute of Aeronautics and Astronautics 


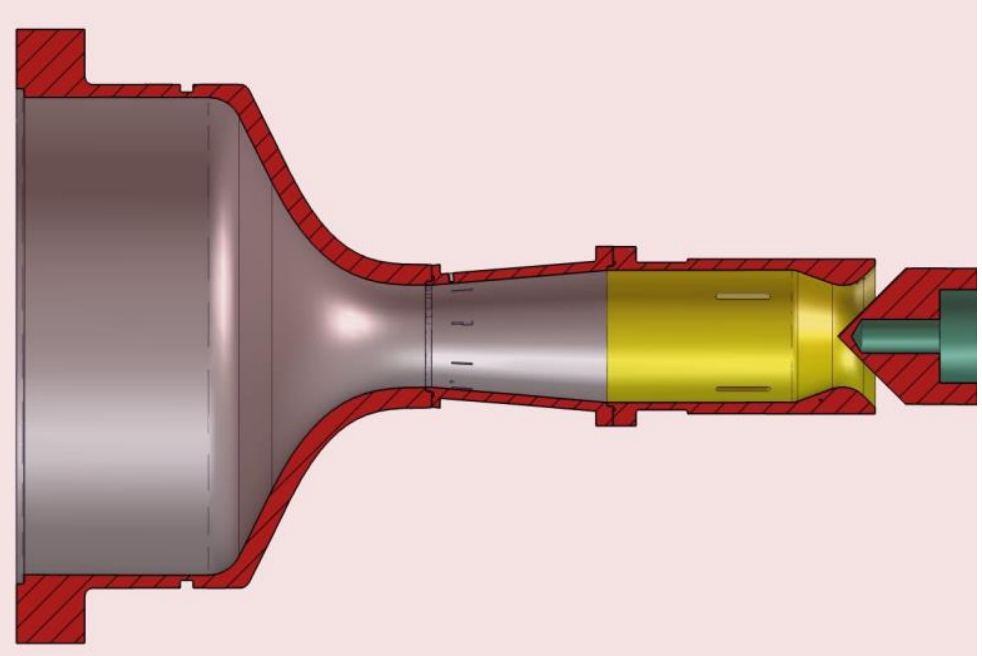

Figure 3. Cross sectional view of the $\mathrm{N}+2$ calibration rig.

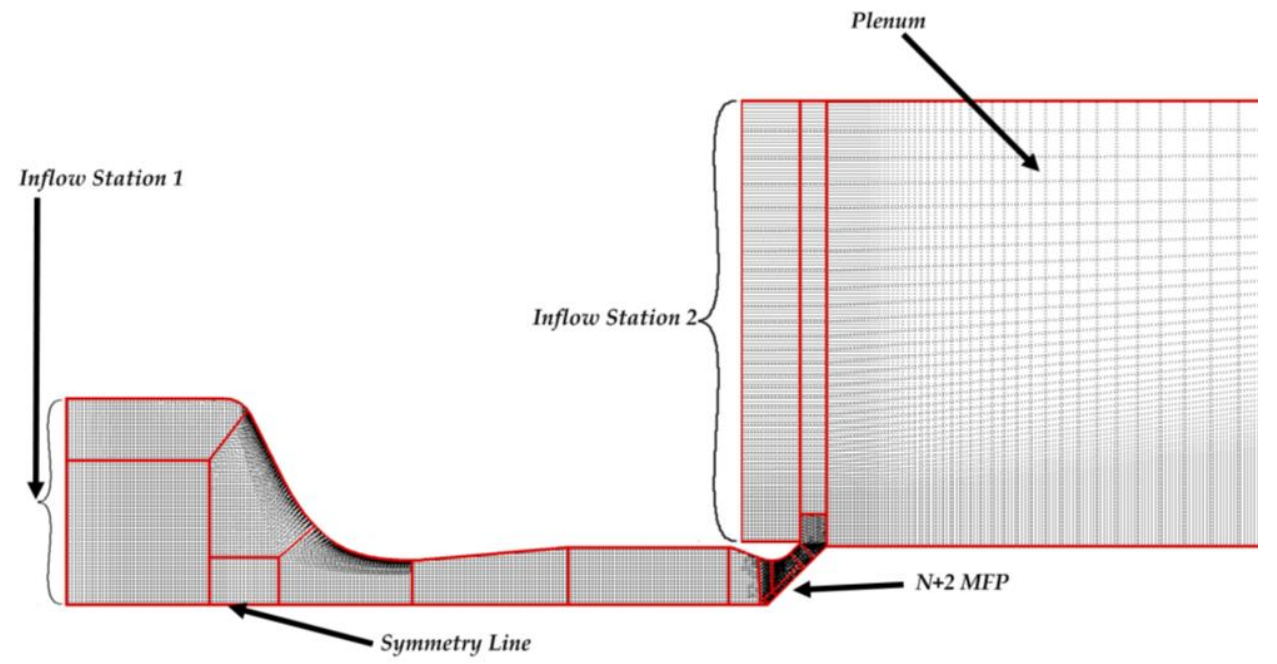

Figure 4. Mesh of the $\mathrm{N}+2$ calibration rig including the plenum 


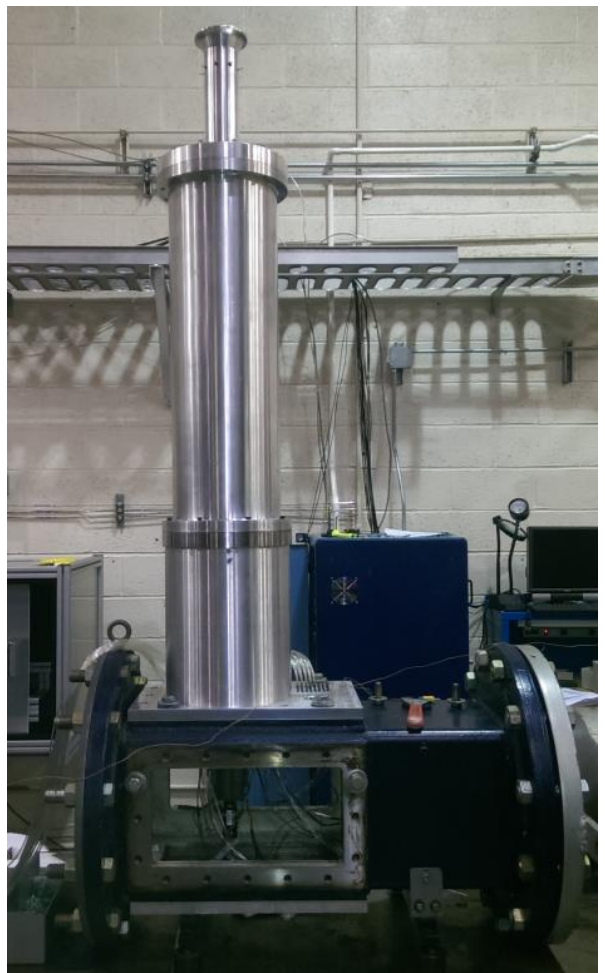

Figure 5. Test geometry w/test section.
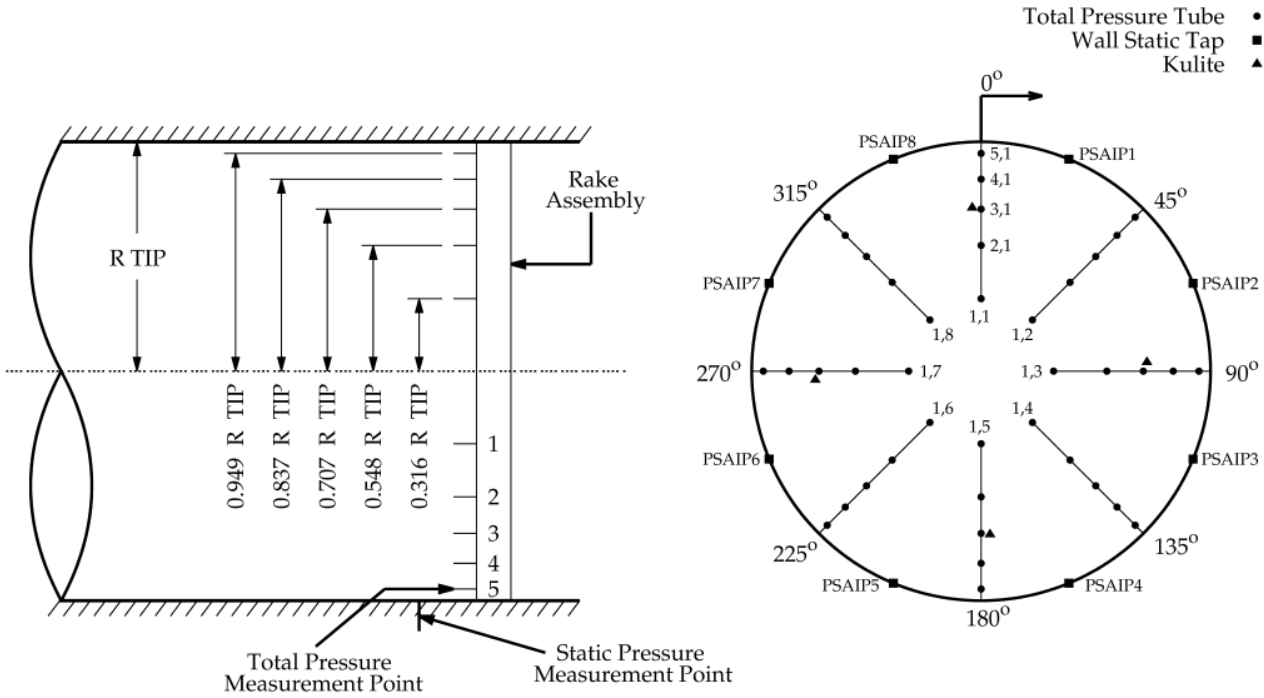

Figure 6. Side view and upstream view of the AIP instrumentation rake. 

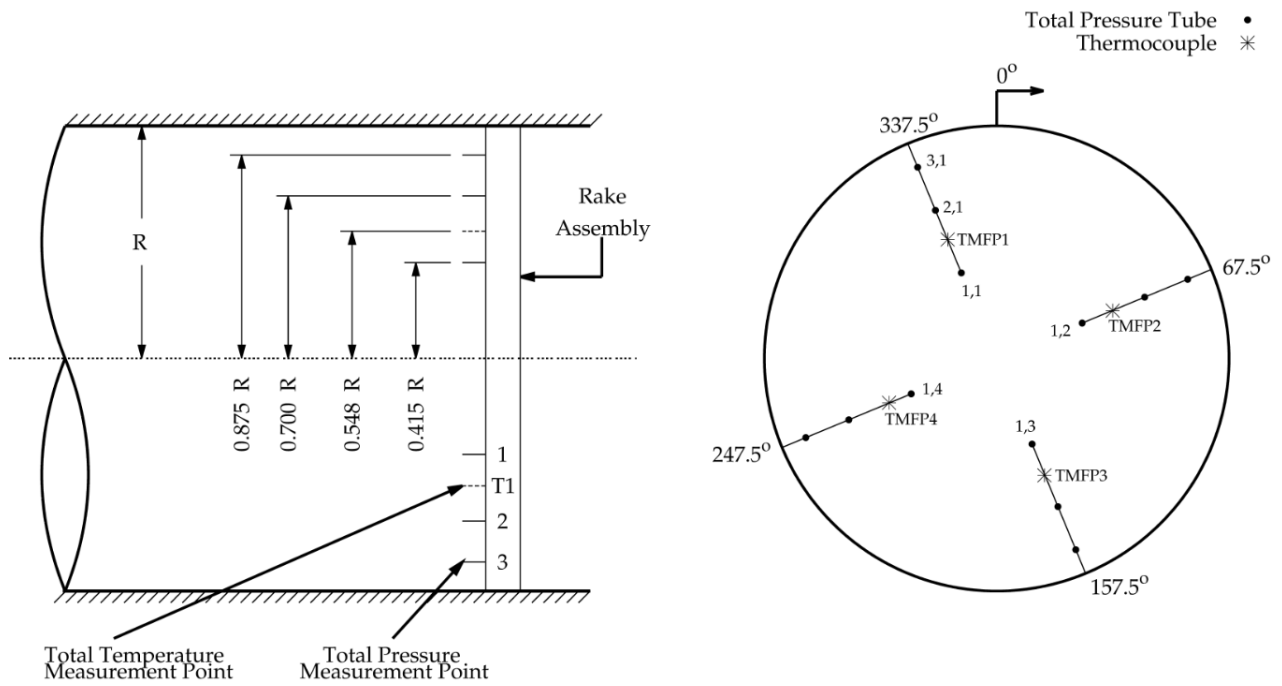

Figure 7. Side view and upstream view of the MFP instrumentation rake

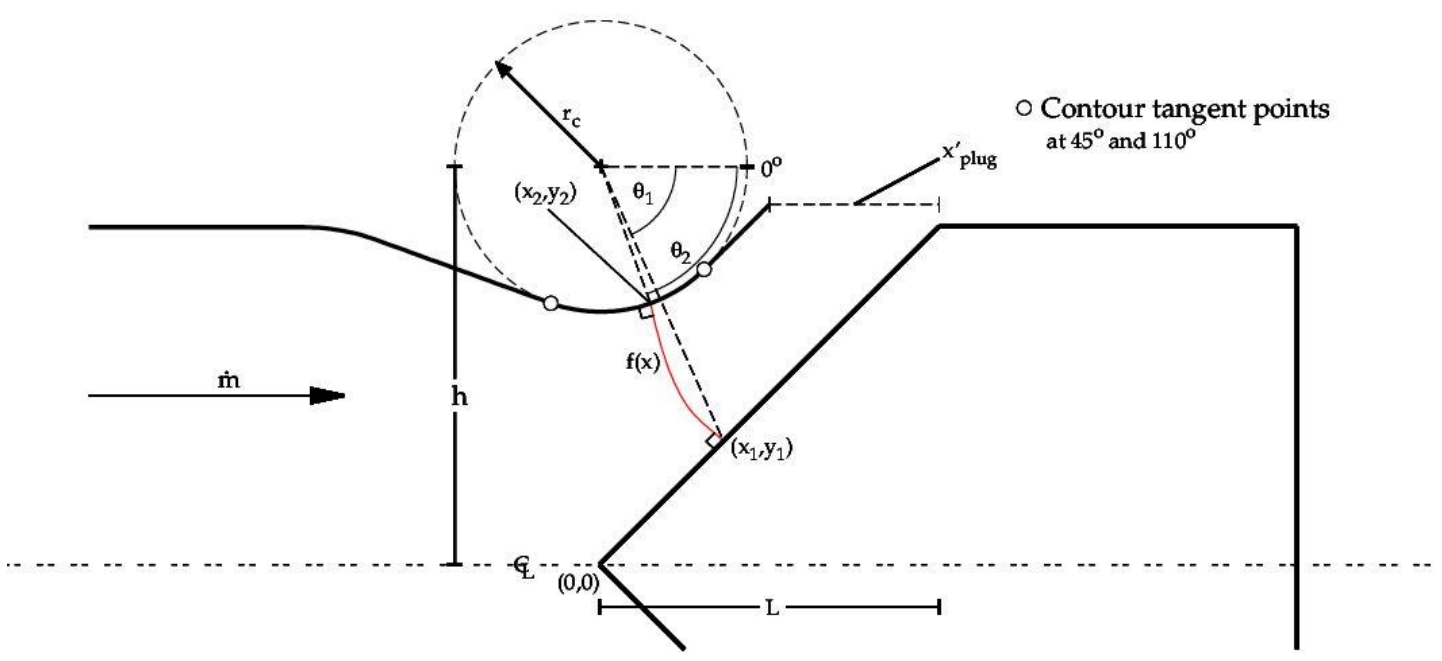

Figure 8. Schematic for calculating MFP minimum area. 
(a)
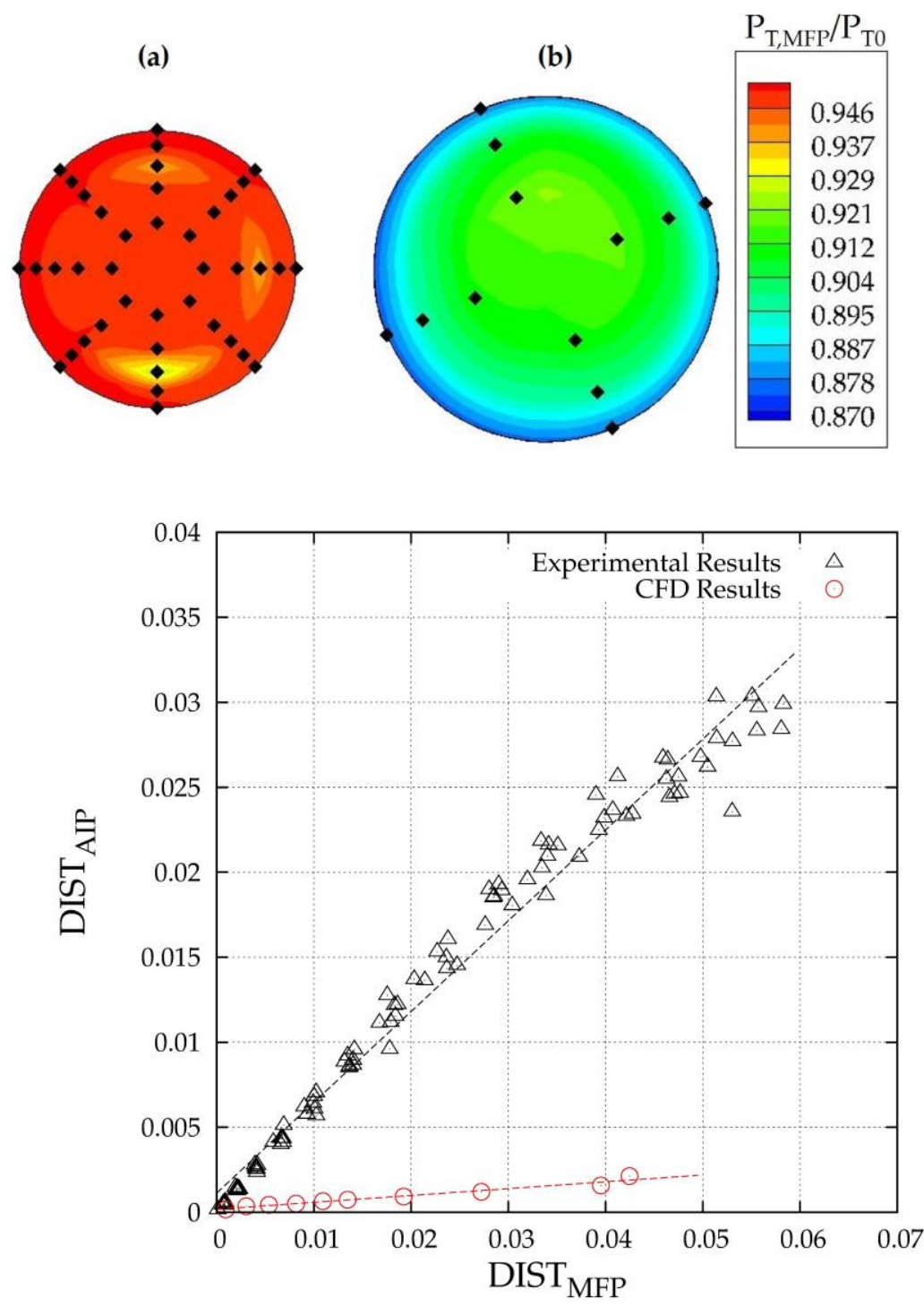

(c)

Figure 9. Pressure variations in non-distorted flow 


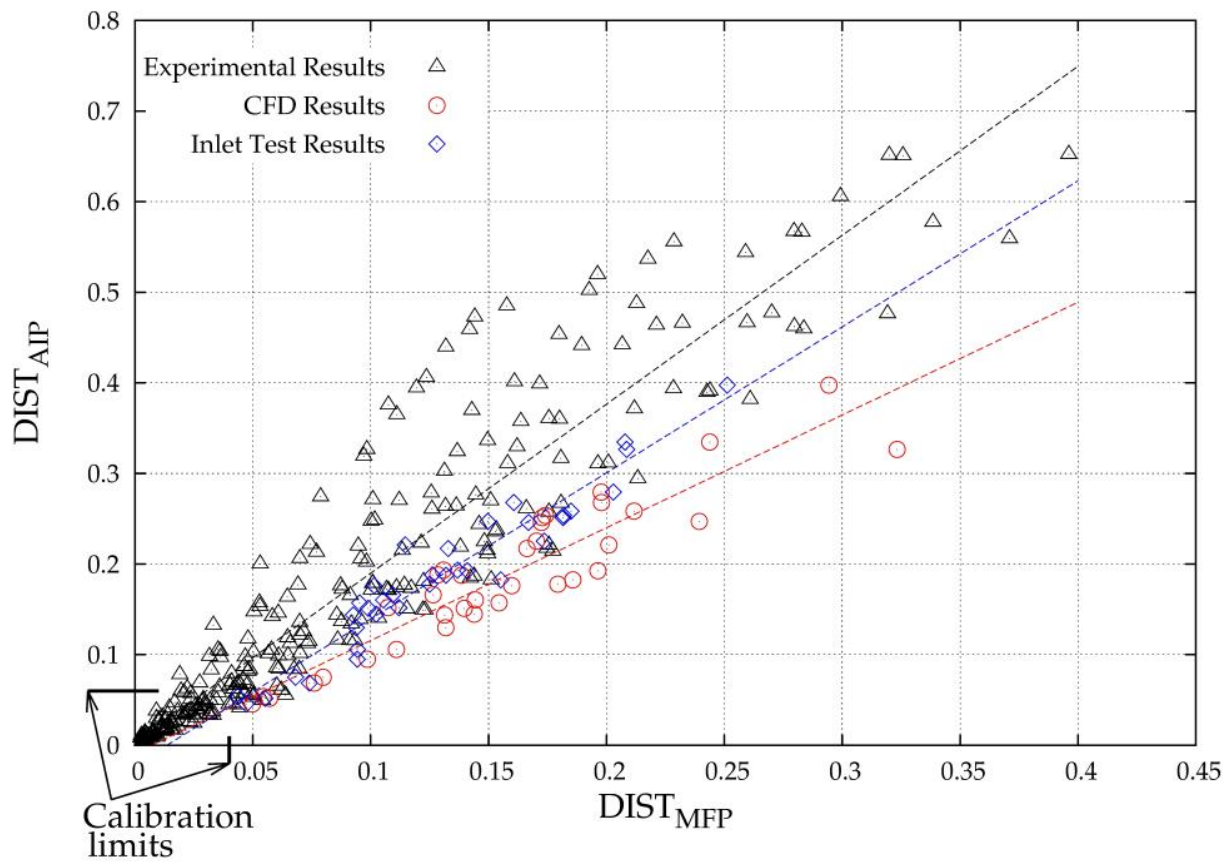

Figure 10. $\quad A I P$ versus $M F P$ distortion.

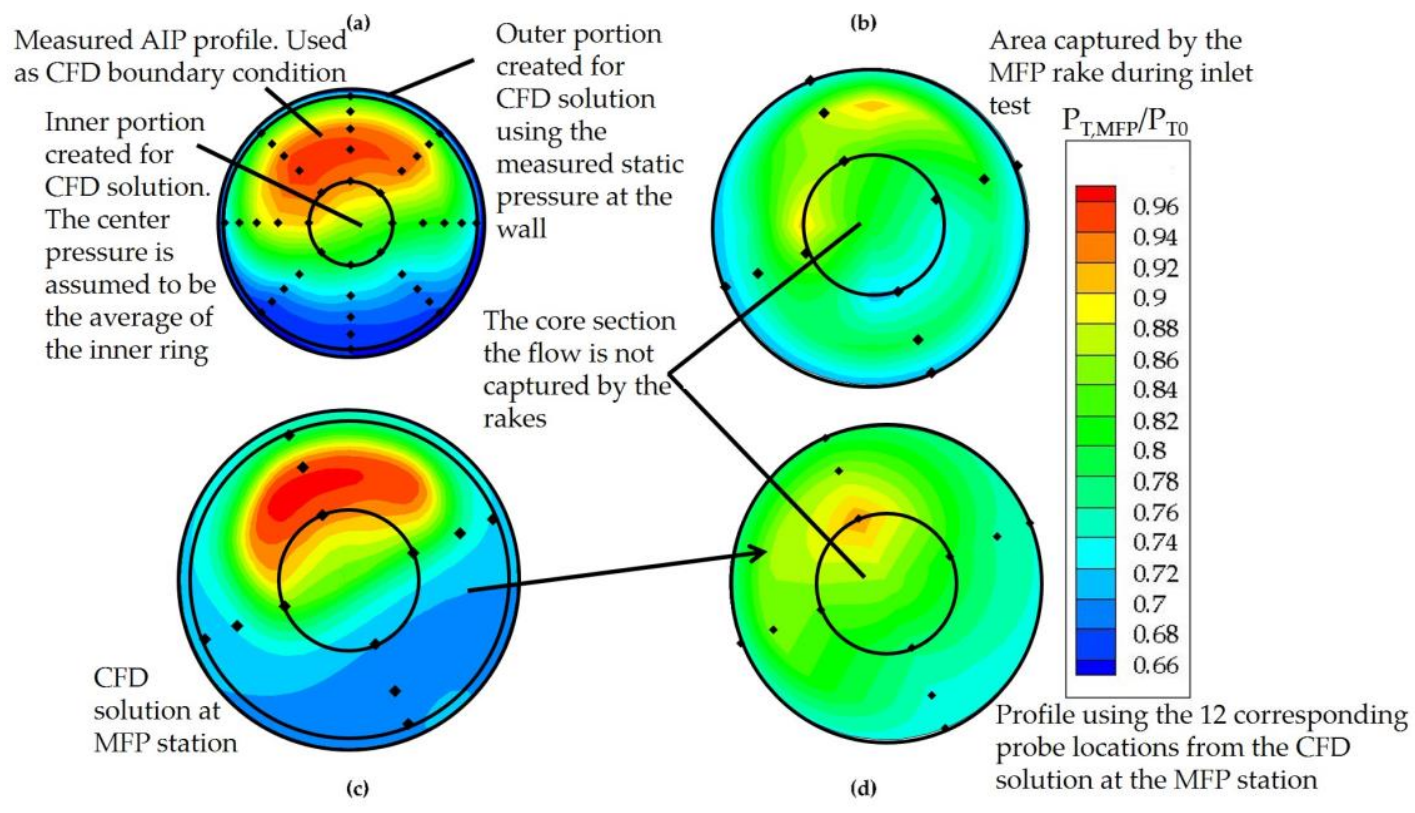

Figure 11. Inlet test and CFD results 


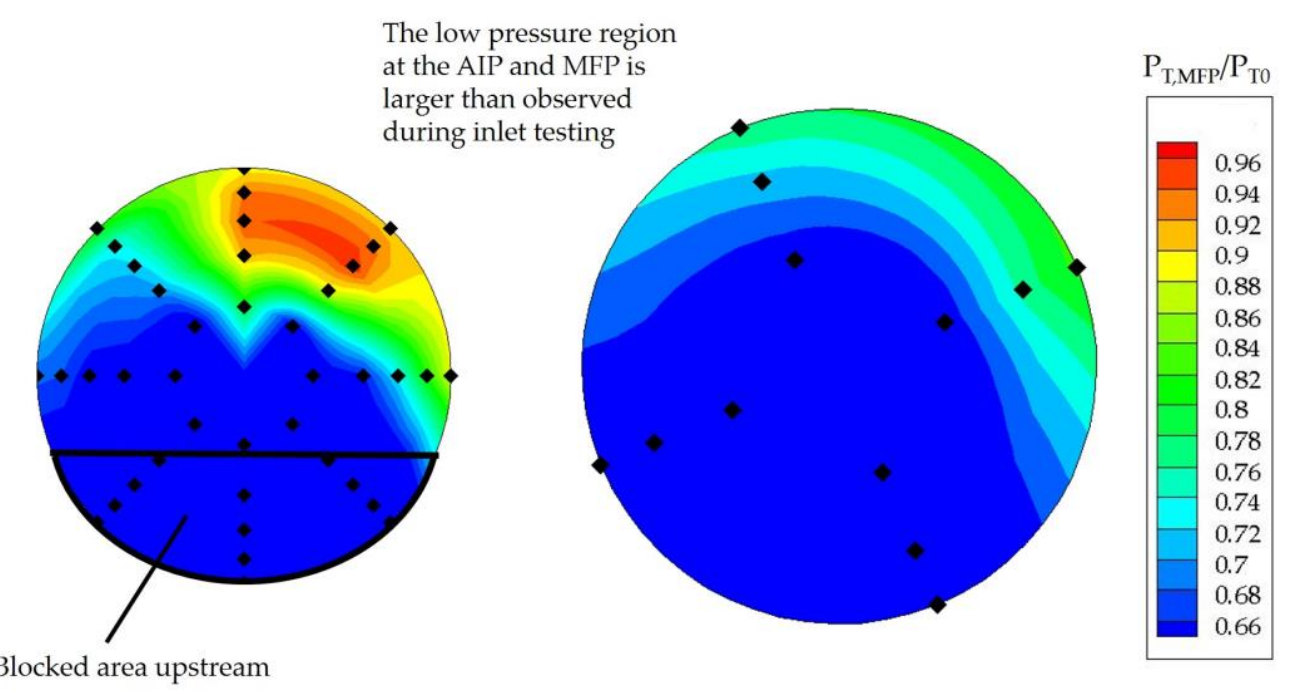

Figure 12. Experimental distortion results for screen 15.1

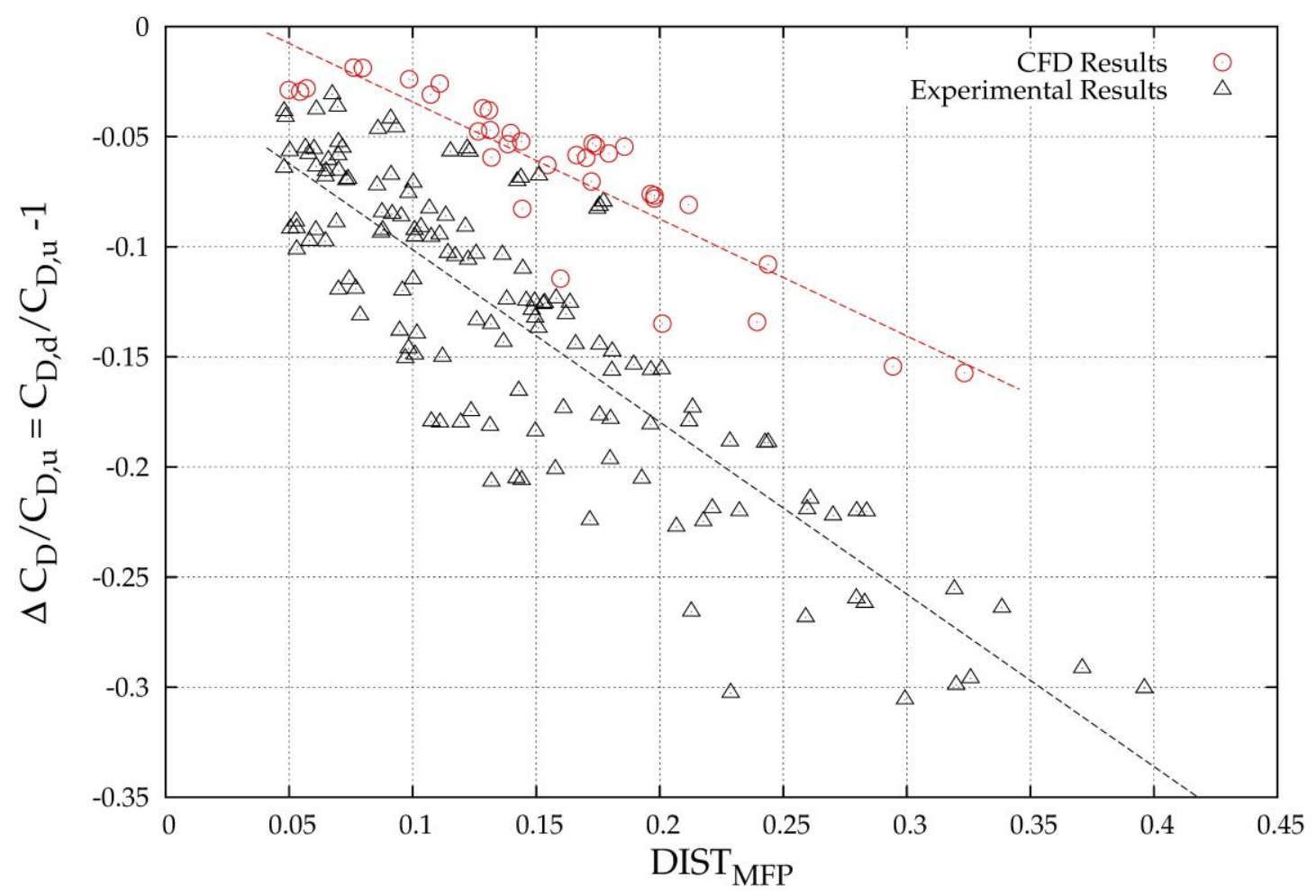

Figure 13. Distortion results for all screens. 

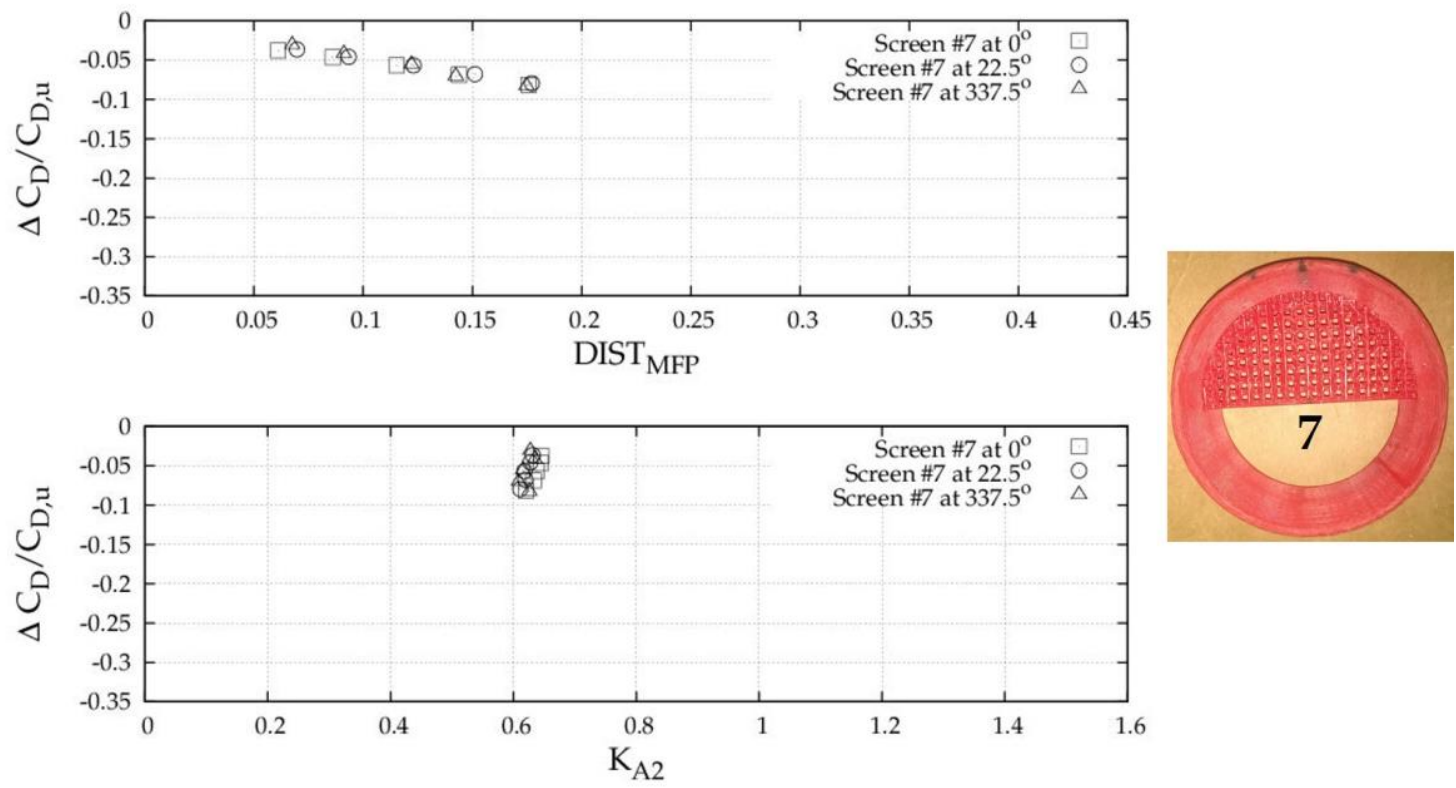

Figure 14. Distortion results for screen 7.
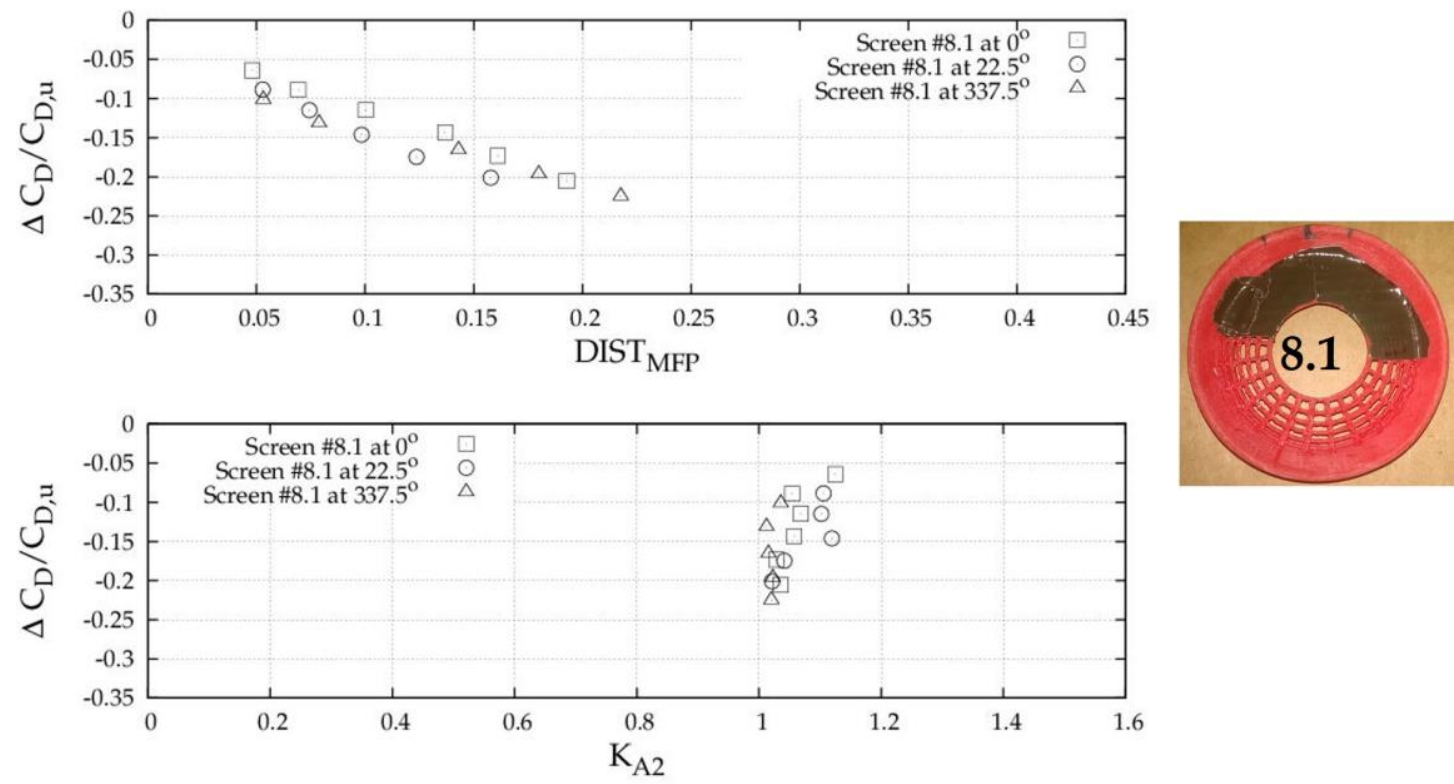

Figure 15. Distortion results for screen 8.1. 

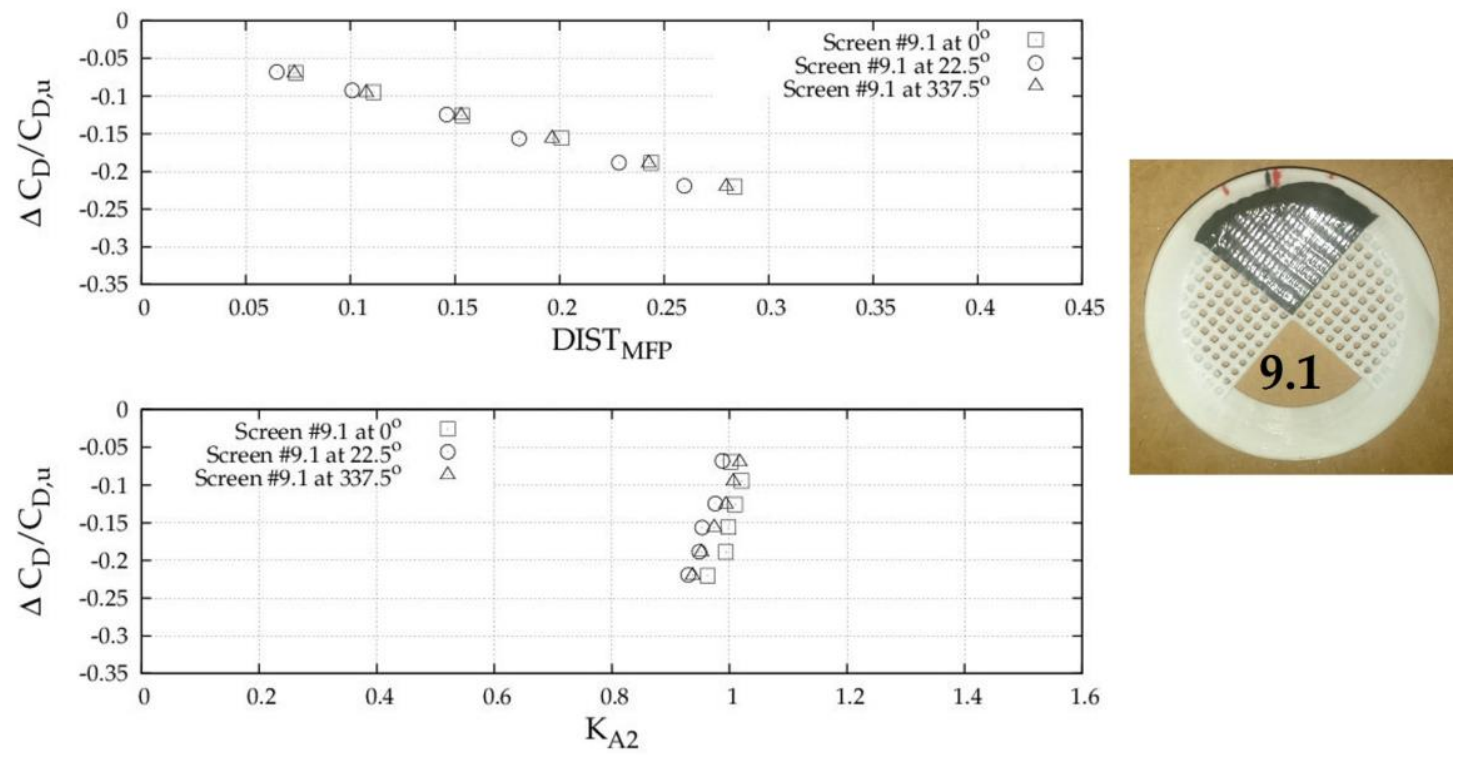

Figure 16. Distortion results for screen 9.1.
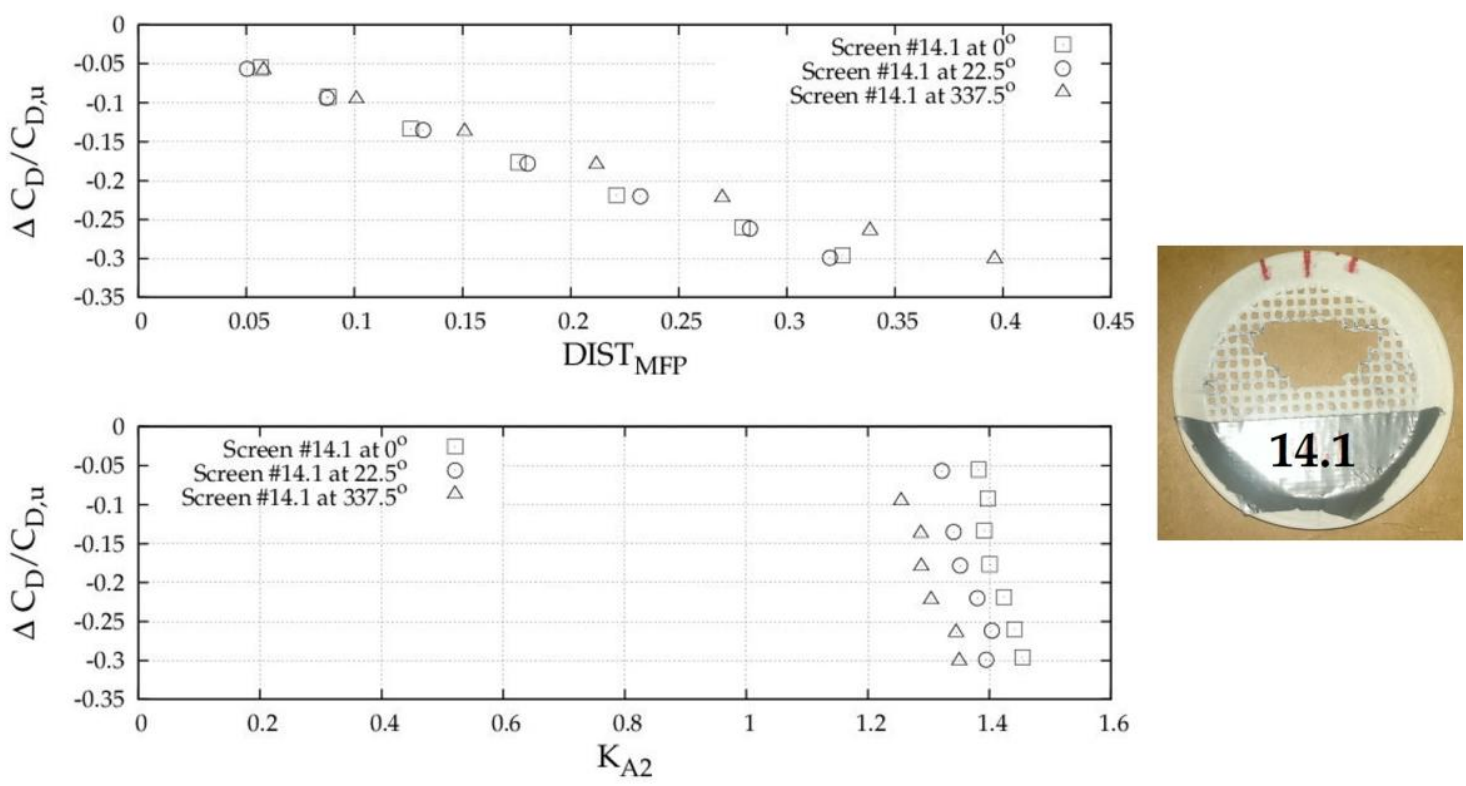

Figure 17. Distortion results for screen 14.1. 

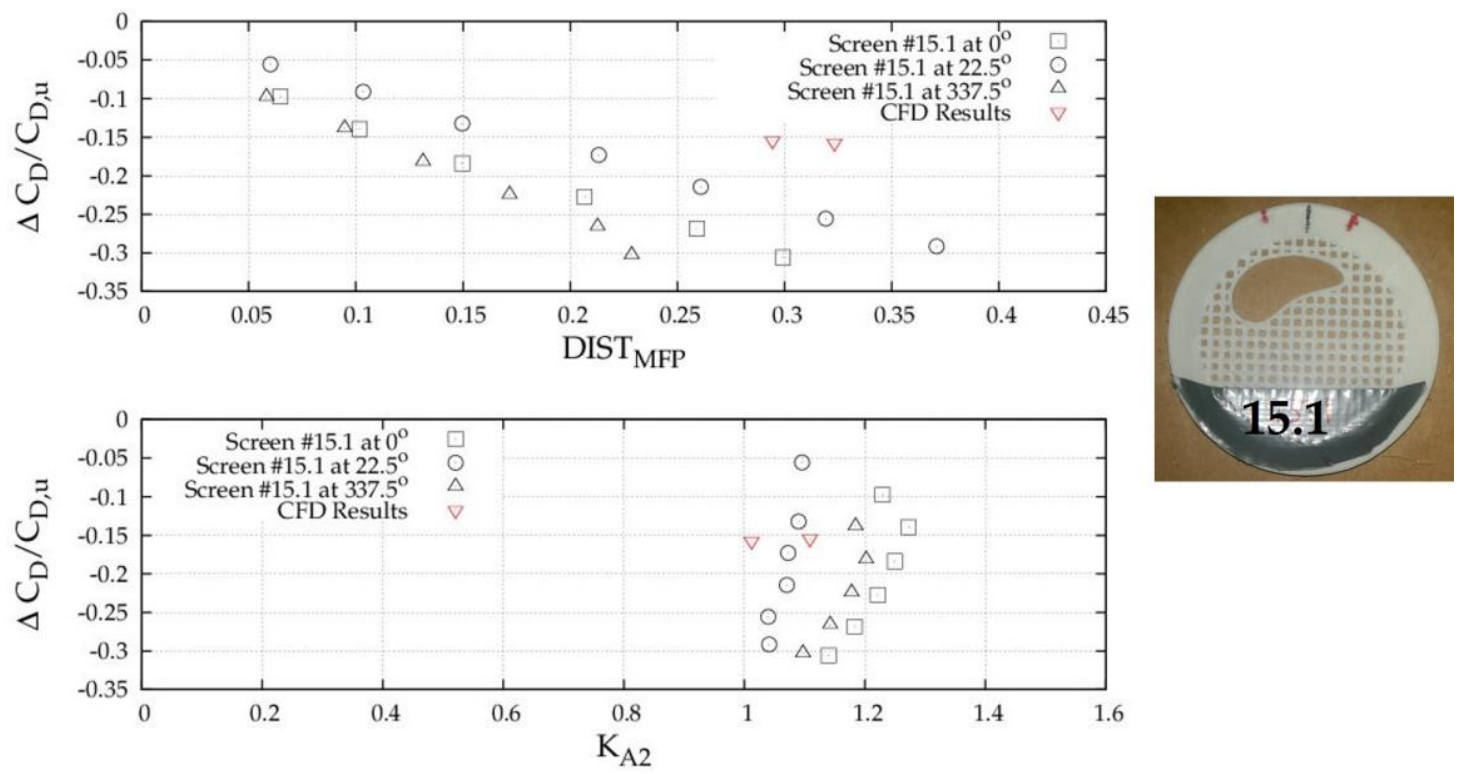

Figure 18. Distortion results for screen 15.1.

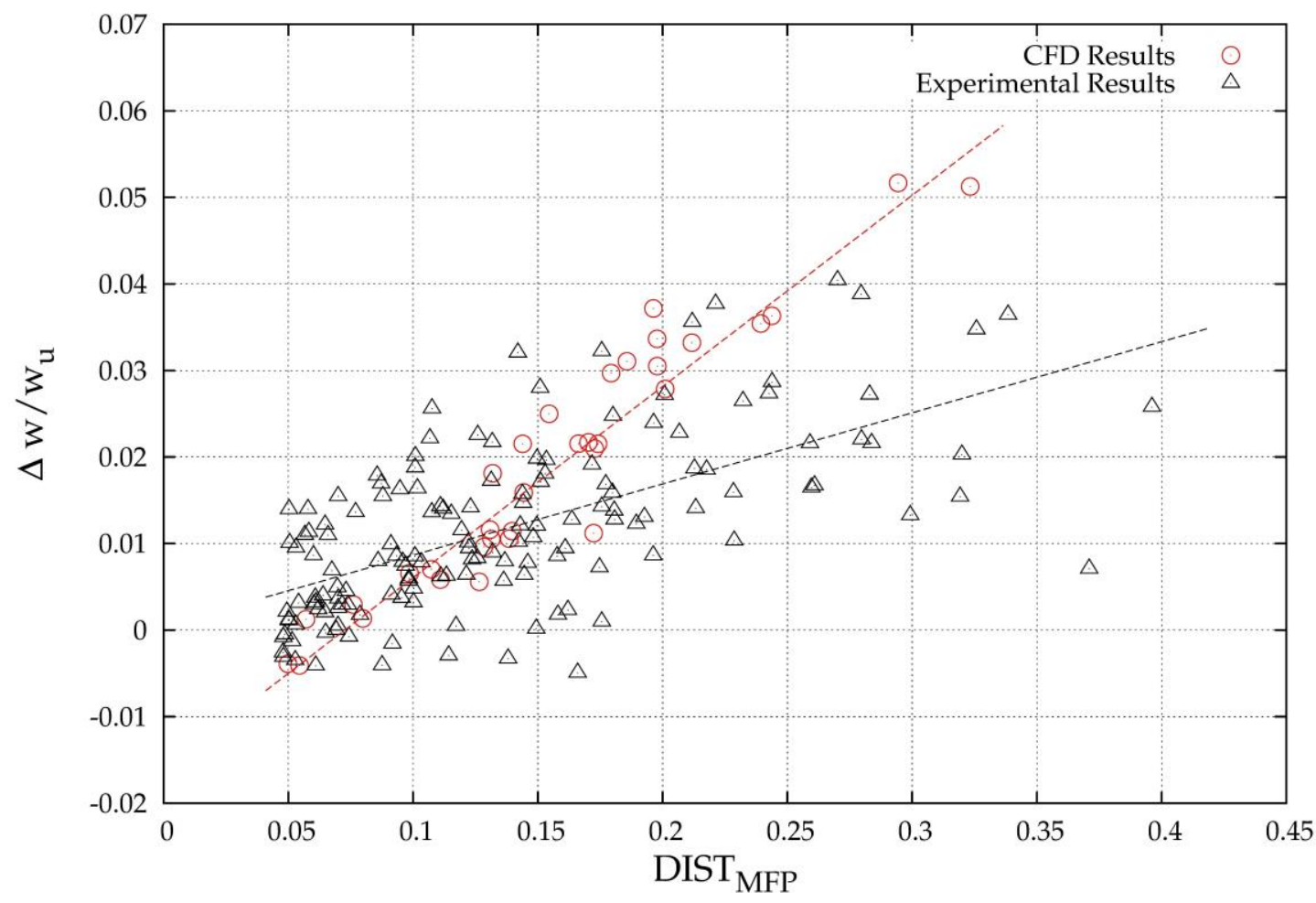

Figure 19. Distortion results with weighted flow corrected by MFP pressure.

\section{Acknowledgments}

Funding from the Supersonics Project of the NASA Fundamental Aeronautics Program is gratefully acknowledged. 


\section{References}

${ }^{1}$ Davis, D. O., and Saunders J. D., "Calibration of the NASA GRC 16" Mass-Flow Plug," ASME, Rio Grande, Puerto Rico, 2012.

${ }^{2}$ Norby, W. P., 1990, "Small Scale Inlet Testing for Low Cost Screening Applications," AIAA Paper 1990-1926, 26th AIAA Joint Propulsion Conference and Exhibit, Orlando, FL

${ }^{3}$ Towne, C., "Wind-US User's Guide, Version 2.0," Glenn Research Center, NASA/TM-2009-215804, Oct. 2009.

${ }^{4}$ Menter, F.R., "Two-Equation Eddy Viscosity Turbulence Models for Engineering Applications,” AIAA Journal, Vol. 32 , No. 8, 1994, pp. 1598-1605.

${ }^{5}$ Georgiadis, N., and Papamoschou, D., "Computational Investigations of High-Speed Dual-Stream Jets,” AIAA Paper $2003-$ 3311, May 2003.

${ }^{6}$ Georgiadis, N.J., Rumsey, C.L., Yoder, D.A., and Zaman, K.B.M.Q., "Turbulence Model Effects on Calculation of Lobed Nozzle Flowfields," Journal of Propulsion and Power, Vol. 22, No. 3, 2006, pp.567-575.

${ }^{7}$ Sasson, J.,"Numerical Calibration of Mass Flow Plug for Inlet Testing”, AIAA Propulsion and Energy, 2015 (to be published).

8"ARP 1420", SAE, Warrendale, PA, 2002.

9"ARP 246", SAE, Warrendale, PA, 2012. 